\title{
An assessment of the current state of Bioinformatics education
}

\author{
Martin Gollery ${ }^{*}$ \\ Center for Bioinformatics, University of Nevada at Reno, Department of Biochemistry / MS330; \\ E-mail: marty.gollery@gmail.com; Phone: +775 784 7042; * Corresponding author \\ received November 08, 2006; published online November 14, 2006
}

\section{Editorial Message:}

Several years ago, George Mason University instituted the first Ph.D. program in bioinformatics in the world. This step was followed by many other organizations, and students flooded into these programs. By the end of the nineties, bioinformatics was one of the hottest fields in all of science, and college Deans were extremely proud of their new programs, for they were evidence that the college was modern and progressive.

Today it is possible to get a bachelor's, masters or Ph.D. at literally scores of schools. The University of Manchester even has an online bioinformatics masters' degree program. Unfortunately the job prospects for the students, while not dismal by any means, are not as promising as they seemed to be a few years ago. Bioinformatics companies are fewer and far between than they once were. During the heyday of the genome era, when money was being thrown at every idea, it seemed that there would be jobs for all the dot-com refugees. Salaries have suffered as well, and some have transitioned into other, higher paying programming jobs that require less training. This is particularly true with those coming from the Computer Science side of the field. It is much easier to find a job developing accounting databases than it is to find one developing algorithms for computational biology.

Today the Bio-jobs bulletin boards are full of recent graduates bemoaning the state of affairs, as many of them report that they cannot find a position in their chosen field. Certainly, the slowdown in the biotech industry is to blame, but part of the problem is that the term bioinformatics is too broadly used. While many people think about sequence based bioinformatics, I have heard the term being used for those who analyze $\mathrm{x}$-ray crystallographic data and also for those who make computational models of the brain. People, that is, who may never work with amino acid or nucleotide sequence at all. Simply because both are referred to as bioinformaticists does not mean that the two skill sets are interchangeable, any more than zoologist is interchangeable with a botanist. Both are biologists, but one would not be able to take over the duties of the other, except, of course, in rare circumstances.

I was once asked to outline a bachelor's degree program in bioinformatics, and I did so. But I couldn't help wondering if this was really the best way of serving the student's needs. Perhaps we need a new paradigm: I maintain that what is most needed in the world is a combination of skills. Students graduating in biology or biochemistry four years from now ought to know their way around the Linux command line. They also should know when to use BLAST and when to do a PFAM search. They should know what tab output is and how to bring it into a spreadsheet or to a database. They should be able to write a Perl script.

University educators need to face the fact that the world has changed. It has been said that professors prepare students for the world as it was when the professor graduated, but this is not sufficient anymore!

There will always be a need for people who are specialists in bioinformatics but that need is limited. What is most needed are biologists who have a basic understanding of bioinformatics. A combination of wet lab skills and computational expertise will make a powerful combination that will be useful in almost any situation!

Editorial: M. Gollery

Citation: Gollery, Bioinformation 1(7): 247 (2006)

License statement: This is an open-access article, which permits unrestricted use, distribution, and reproduction in any medium, for non-commercial purposes, provided the original author and source are credited. 